\title{
NYLIDRIN HCL: A BETA-SYMPATHETIC STIMULANT IN THE MANAGEMENT OF HAEMORRHAGIC SHOCK
}

\author{
GuY M. BotTeau, M.d. and Jean-Paul DechêNe, M.D. $\dagger$
}

IN RECENT YEARS several writers ${ }^{1-3}$ have suggested an entirely different approach to the management of haemorrhagic shock near the irreversible stage. Vasopressors such as noradrenaline and metaraminol (Aramine) which keep the blood pressure up by increasing the peripheral resistance were until recently the most popular medications in shock, once the blood volume had been adjusted. Today, increased mention ${ }^{2}$ is made of the advantages of using agents which block adrenergic constrictor impulses in order to promote peripheral blood flow by reducing peripheral resistance. This type of treatment, alpha sympathetic blockade, is commonly employed in animals, but is rarely used clinically in shock management. It is known that the initial stage of shock is often associated with a significant restriction of circulation to protect vital organs such as the brain and the heart, and at least initially to protect the pressure-dependent circulation of the kidneys. But vasoconstriction, if maintained, can bring on an irreversible stage of shock by opposing and interfering with the successful maintenance of an adequate cardiac output.

This self-limiting reflex of preservation rapidly begins to fail. A fatiguing myocardium no longer can maintain an adequate output against the forces of a restricted volume in a markedly constricted arteriolar vascular system. Impaired venous return and often splanchnic pooling add further stress to the maintenance of cardiac output. As output is reduced the resultant fall in renal circulation markedly restricts its function, and oliguria ensues. If left unattended this pattern of failing output in the face of extensive vasoconstriction and oliguria leads to myocardial exhaustion and circulatory collapse with a 100 per cent mortality. In many instances, even when they are promptly instituted, efforts to reverse the degenerative tendency of these circumstances (volume replacement to offset the failing cardiac output or volume replacement and vasopressor agents to bolster output and raise arterial pressure to levels consistent with appropriate renal perfusion) rarely succeed more than 50 per cent of the time. In other words, the circumstances described above seem to lead invariably to an "irreversible state" from which perhaps only providence and good fortune permit the salvage of, at best, every other patient.

It occurred to many investigators, some of whom were mentioned earlier, that a certain cyclicity attends the events that lead to "irreversible shock." Trauma (blood loss, toxin, etc.) leads to vasoconstriction, poor tissue perfusion, reduced venous return, reduced cardiac output, and a fatiguing myocardium labouring to overcome increased resistance caused by vasoconstriction. Therefore, rational

-Head, Cardiac Laboratory, Institute of Cardiology, Hôpital Laval, Quebec.

tHead, Department of Anesthesia, Hopital Laval, Quebec. 
therapy might be directed to the interruption of the cycle before it spins on to irreversibility. Agents that could inhibit the vasoconstriction induced by the sympathetic alpha receptor have been employed with some considerable degree of success. However, this too left much to be desired because the cutaneous tissue is rich in vasculature controlled by alpha sympathetics and, as a consequence of the use of alpha blockade, marked surface vasodilatation occurred which sequestrated a significant volume of blood from the central circulation. Also, as the efferent arm of the baroreceptor mechanism is linked to alpha receptors for the maintenance of blood pressure, this loss of control results in appreciable fall in blood pressure. Therefore, despite a reduced arterial resistance, this fall in mean arterial pressure could compromise flow, and further reduction in central venous pressure might adversely influence cardiac output.

The possibility of the existence of a pharmacodynamic agent that could intercede in the vasoconstriction-diminished cardiac output cycle so pathognomonic for irreversible shock led us to our current study of Nylidrin $\mathrm{HCl} .{ }^{*} \mathrm{Nylidrin} \mathrm{HCl}$ is an amine chemically related to epinephrine and ephedrine and pharmacologically active as a beta-sympathetic receptor stimulator. It will be recalled from the work of Ahlquist ${ }^{4}$ that beta-sympathetic stimulation is associated with active vasodilatation of coronary and deep muscle vasculature. (Recent work has been reported where this influence is also mediated to cerebral and splanchnic vessels as well.5,14-16) Ahlquist established further that beta-sympathetic stimulation has no influence on cutaneous vasculature, and that it possesses definite inotropic and chronotropic influences on the myocardium.

\section{Materuals and Procedure}

Twenty-five healthy dogs weighing from 10 to $20 \mathrm{~kg}$. were anaesthetized with a Halothane-Ether mixture ${ }^{6}$ after tracheal intubation under transient curarization. The intubation was performed with the Portex cuff-type catheter connected with a Boyle anaesthetic apparatus and the Azeotec vaporizer. No premedication was administered, to avoid disturbing the physiological parameters. A polyvinyl catheter was inserted into the femoral artery as far as the abdominal aorta, and another was placed in the femoral vein up to the inferior vena cava. Each animal received three mg. per kilogram of body weight of aqueous heparin intravenously and was then bled with a portable-tank technique containing sodium citrate. Systemic arterial blood pressure was maintained at an average of $40 \mathrm{~mm}$. $\mathrm{Hg}$ for three hours.

The cardio-respiratory safety factor of the halothane-ether mixture is most important, and its advantages have already been emphasized. ${ }^{7}$ This azeotropic mixture produces a highly satisfactory oxygenation for cardiopulmonary surgery, and its bronchodilating effect serves to improve ventilation in the patient. Slightly lowered blood pressure and the few scanty extrasystoles encountered do not impair the cardiac function. The cardiac output is hardly affected during light anaesthesia.

-Arlidin Hydrochloride, trade name. This investigation was supported by Arlington-Funk Laboratories, Montreal 3, Quebec. 
Electrocardiograms and arterial and central venous blood-pressure tracings were fed to a multiple channel recorder (Electronics for Medicine, DR-8, and Sanborn, Twinviso). The cardiac output was computed from dilution indicator curves (Waters-301A) using the Stewart-Hamilton technique. ${ }^{8}$ The acid-base balance and the $\mathrm{P}_{\mathrm{O}_{2}}$ and $\mathrm{P}_{\mathrm{CO}_{2}}$ were determined with the Siggaard-Andersen nomogram and radiometer method. ${ }^{\ominus}$ Plasma volume was ascertained by the albuminbound iodine-131 (RISA) procedure in some cases and in others calculated by Courtice's method. ${ }^{10}$

Technical difficulties led to the death of three dogs prior to the onset of the second hour of shock. The insufficient data derived from these animals is not included in this study. Each of the remaining twenty-two dogs was kept under observation for approximately six and one half hours after the onset of shock. Shock lasted three to three and one half hours, during which time systemic blood pressure was maintained at an average of $40 \mathrm{~mm} . \mathrm{Hg}$. At random, thirteen animals were selected for treatment with $0.5 \mathrm{mg}$. $/ \mathrm{kg}$. of $\mathrm{Nylidrin} \mathrm{HCl}$ and approximately 100 c.c. of sodium bicarbonate solution ( $\mathrm{Na} 44 \mathrm{mEq}$./L.) after the third hour of shock and just prior to re-transfusion. The nine other animals were used as controls and were re-transfused without prior treatment after the third hour of shock. The parameters listed above were investigated in all animals before bleeding began, at the end of the second and third hours after bleeding, and again up to three hours after re-infusion.

\section{Results}

\section{Blood Volume}

The blood volume was measured with the radioisotope technique (RISA) in some cases, and in others Courtice's method ${ }^{10}$ was employed. There was a good degree of fit between the two findings. Courtice's method takes the weight of the dog into account (i.e., the approximate blood volume of a dog weighing $12.70 \mathrm{~kg}$. would be $1050 \mathrm{ml}$.). In our animals the average blood volume had been calculated or estimated at $1420 \mathrm{ml}$. (1100 to $2200 \mathrm{ml}$.). From these calculations, it was possible to observe that withdrawal of 52.7 per cent of the blood volume on the average was required to maintain the arterial blood pressure at $40 \mathrm{~mm} . \mathrm{Hg}$ and create a marked state of shock. The haematocrit was hardly affected at all throughout the blood-letting and initiation of severe shock.

\section{Cardiac Output}

The mean cardiac output of all the dogs, before bleeding was undertaken, was 1.72 litres per minute, ranging from 0.79 to 3.15 (Fig. 1). After the dogs were bled to shock level and their arterial pressure maintained at $40 \mathrm{~mm} . \mathrm{Hg}$, repeat cardiac output values were obtained at the second and third hours. The relationship between blood loss and cardiac output is plotted in Figure 1. The mean value for cardiac output at $0.49 \mathrm{~L} . / \mathrm{min}$. correlates well with a blood loss of 52.7 per cent previously determined as an average value for the maintenance of the shock state. Values reported in this and subsequent graphs for cardiac output during the shock state represent for each animal the average value of two 


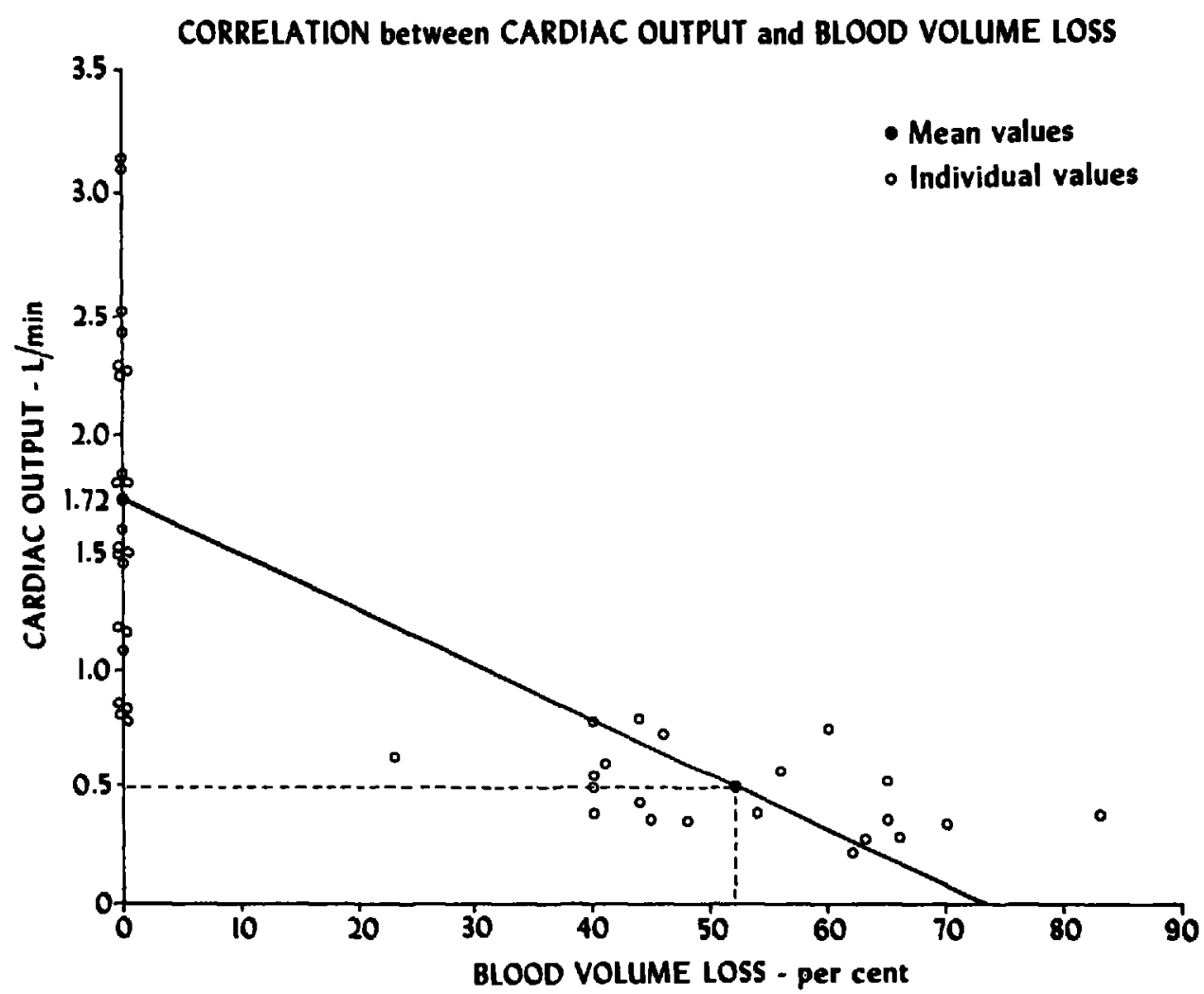

Frcure 1. Correlation between cardiac output and blood-volume loss in 22 dogs, regardless of treatment and survival.

determinations at the second and third hours during the shock state. Separate consideration is given to parameter changes in the treated group of survivors (Fig. 2), in dogs surviving without treatment (Fig. 3), and in dogs not surviving in both groups (Fig. 4).

It can be seen in dogs surviving without treatment (Fig. 3) that after re-infusion of the withdrawn blood, cardiac output in three dogs $(1,3,22)$ rose significantly from the levels present during shock to within 80 to 90 per cent of pre-shock levels and in two dogs $(20,24)$ to slightly higher than pre-shock levels. In dogs surviving with treatment $(0.5 \mathrm{mg} . / \mathrm{kg}$. prior to re-infusion), cardiac output in every instance rose to levels often significantly greater than values obtained prior to the onset of shock. The significance of this observation is perhaps more clearly appreciated when the data obtained from non-survivors are reviewed (Fig. 4). Here it can be seen that with only one exception (that of a treated animal, incidentally) post-infusion cardiac output failed to approach initial output values within reasonable limits. It is also of interest to note that dog \#23 in this group (treated) more nearly approached the dynamic changes seen in surviving animals. While it did not ultimately survive, it did remain alive much longer than other animals in this group.

Two other characteristics of this group distinguish it from the survivors. Firstly, 


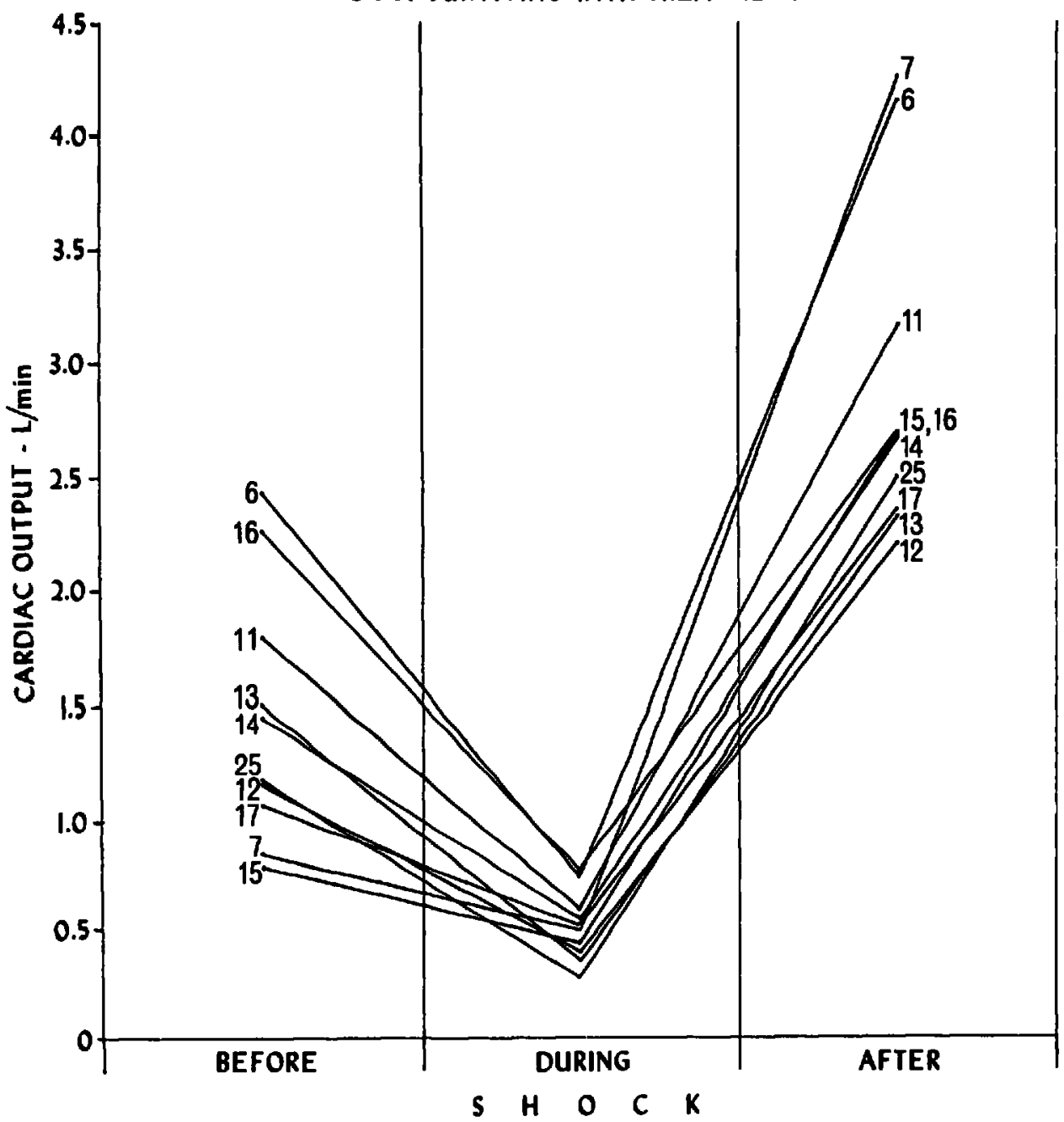

Figure 2. Ten out of thirteen dogs treated with Nylidrin $\mathrm{HCl}$ and sodium bicarbonate survived the $3 \%$ hours of shock. Note that cardiac output rose significantly after blood retransfusion.

in two treated and two untreated animals, the decline in cardiac output from initial to shock state exceeded the average fall in the other groups by a significant degree. This could account for their failure to survive far enough into the post-infusion state to permit further evaluation. Perhaps too-rapid blood-letting or poor cardiac reserve was responsible for the grossly inordinate changes which seemed to militate against survival. Secondly, the average mean cardiac output $(0.369 \mathrm{~L} . / \mathrm{min}$.) of three of the animals ( 2 untreated and 1 treated) that survived far enough into the post-infusion state for evaluation to be made was much below the average value $(0.430 \mathrm{~L} . / \mathrm{min}$.) of all surviving animals; and in addition an average of 60.3 per cent of blood volume had to be removed from them for maintenance of a shock state with pressures at $40 \mathrm{~mm} . \mathrm{Hg}$, as opposed to an average of 52.0 per cent from survivors. 


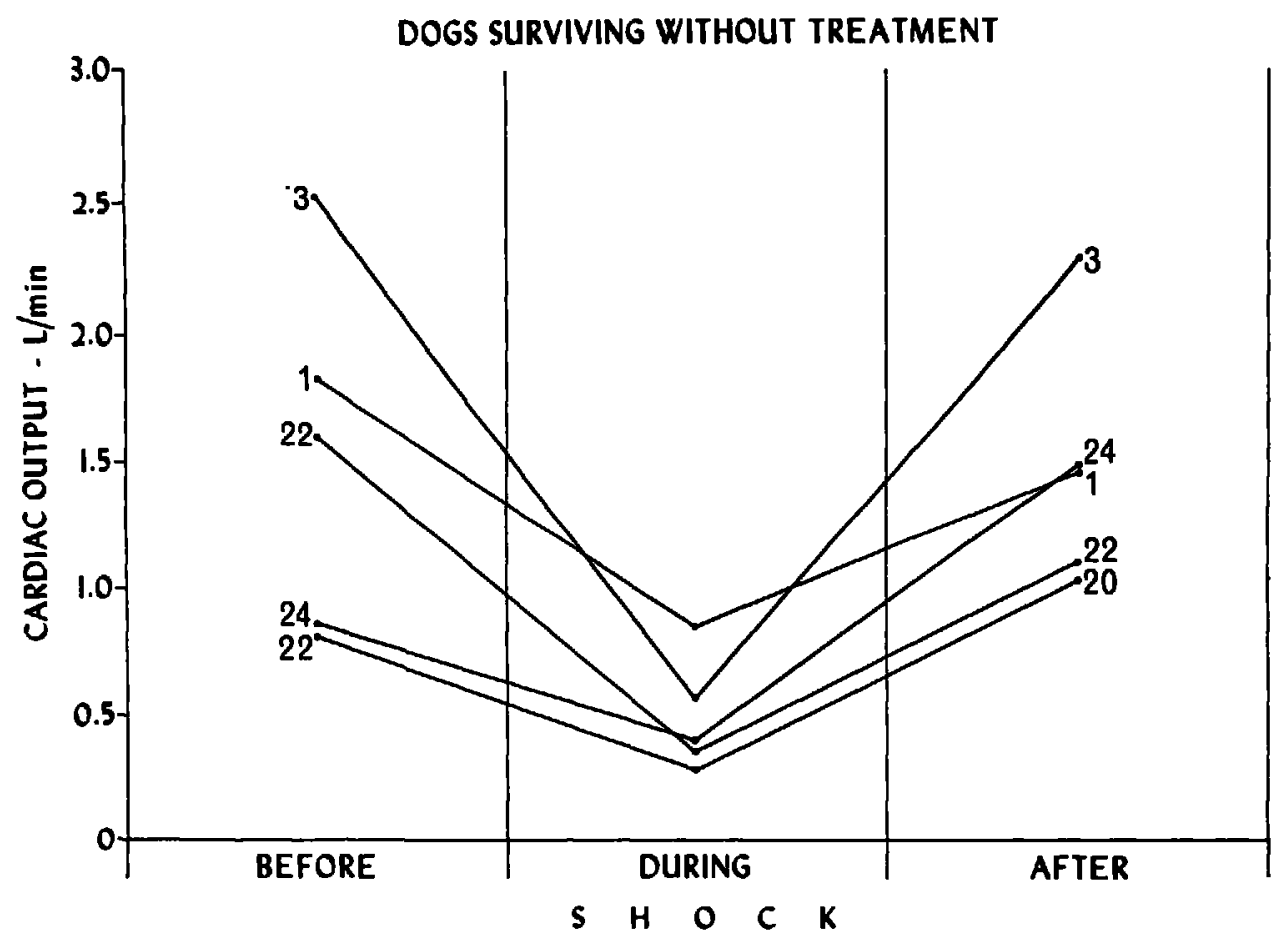

Figune 3. Five dogs survived without treatment with Nylidrin $\mathrm{HCl}$ and sodium bicarbonate. Note that cardiac output was slightly less after retransfusion process.

\section{Arterial Blood Pressure}

The initial arterial blood pressure in all animals averaged $120 \mathrm{~mm} . \mathrm{Hg}$ after intubation and general anaesthesia with the Fluothane-Ether mixture. Throughout the shock period, all animals were maintained for up to three and one half hours at an average arterial pressure of $40 \mathrm{~mm}$.Hg. After re-infusion blood pressure rose in all animals to an average of $80 \mathrm{~mm}$.Hg. In the animals which failed to survive, this level was maintained for approximately 30 minutes, then the arterial blood pressure dropped gradually, and bradycardia set in, along with arrhythmias which terminated in cardiac arrest. The pressure in treated survivors was from 5 to $20 \mathrm{~mm} . \mathrm{Hg}$ lower than in untreated survivors. These variations, however, demonstrated no statistically significant difference, nor could significant differences be determined for the observation that treated animals showed a return to initial pressure values generally 20 minutes earlier than did the controls. Significance was however demonstrable in the calculated differences in peripheral resistance between surviving groups.

\section{Peripheral Resistance}

In the absence of anomalous circulation (arterio-venous shunts, etc.) cardiac output (flow), in relation to pressure (mean arterial), permits through adaptation of Poiseuille's Law the determination of total peripheral resistance (TPR). In

-The quantity of fluid flowing from a narrow tube (one comparable in size to the small arteries) is directly proportional to the pressure gradient, the viscosity, and the fourth power of 


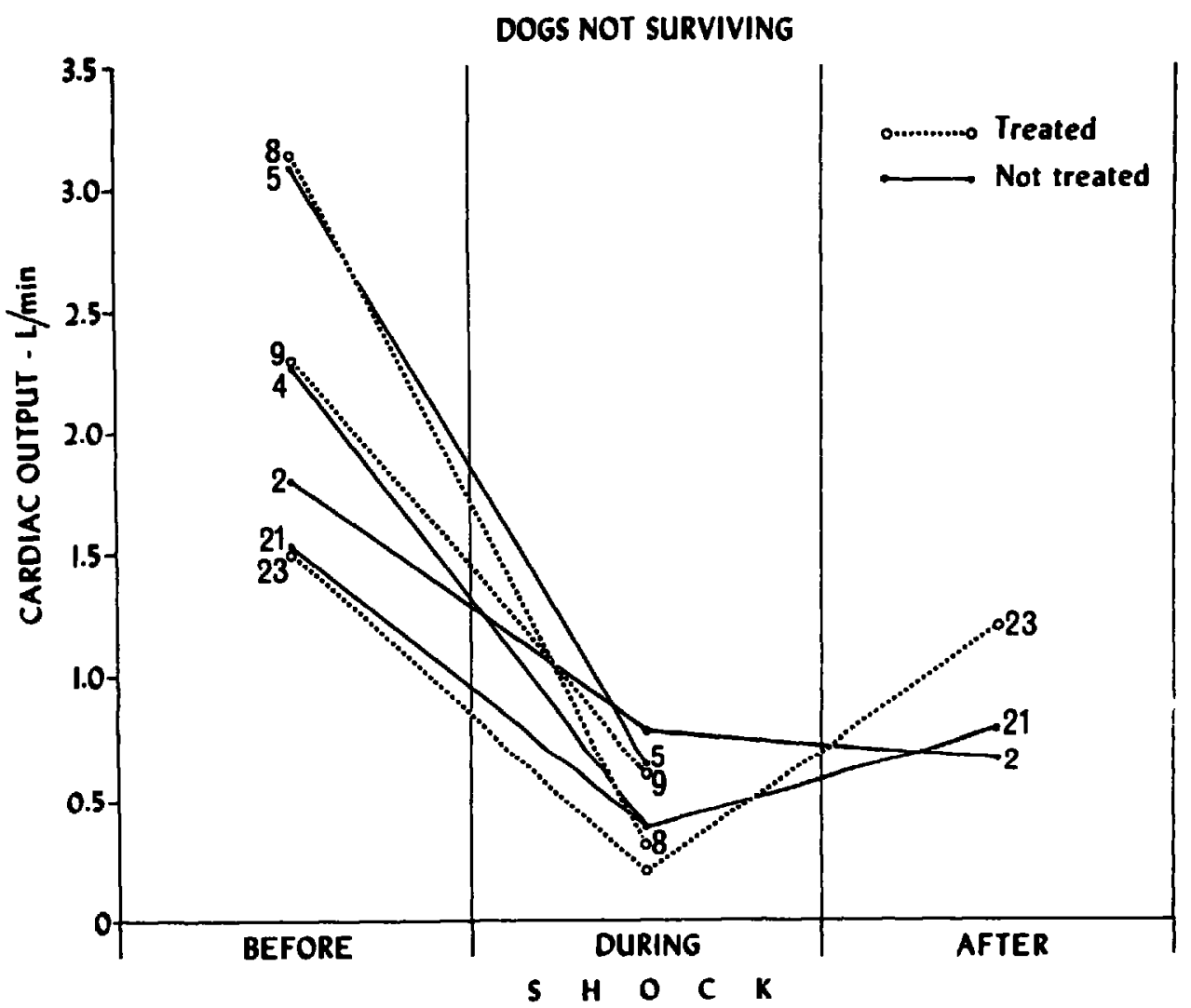

Ficure 4. Four untreated and three treated dogs died after retransfusion. Note that cardiac output in three cases showed little variation after all the blood was returned to the animal.

this manner, TPR was calculated for five dogs surviving without treatment and ten dogs surviving with treatment. These mean values are plotted in Figure 5. It can be noted that initially and throughout shock states no appreciable difference in TPR exists between groups. However, after re-infusion of pooled blood the treated group shows a statistically significant reduction in TPR. Regrettably, too few of the non-surviving dogs lived long enough to permit the inclusion of meaningful data, although it is obvious even by casual comparison of Figures 2, 3 , and 4, that the TPR would be significantly higher in the non-surviving group than in either surviving group. Average values derived for the treated group in dynes $/ \mathrm{sec} . / \mathrm{cm} .^{-5}$ were initially 6522 , during shock 9302 , and at recovery 4109 . In the untreated group, average values of TPR at similar intervals were 7594, 9174 and 7940 respectively.

Nylidrin $\mathrm{HCl}$ significantly increased cardiac output and lowered peripheral resistance during the critical period after replacement of blood volume. Inasmuch as the dynamics of blood flow relate to output and resistance, the alterations induced by Nylidrin $\mathrm{HCl}$ decidedly favour improved peripheral tissue perfusion.

the diameter of the tube; the mean lineal velocity of the current is proportional to the cross arc of the tube, the pressure gradient, and the viscosity coefficient. 


\section{Acid-Base Balance}

A sample of arterial blood was taken before blood letting, at the second and third hours of shock, and again after re-transfusion of blood in order to assess the metabolic components throughout the shock. The severity of metabolic acidosis appeared to be proportional to the duration and intensity of the shock. That is to say, acidosis (or more correctly a depressed $\mathrm{pH}$ ) was observed to be directly parallel to circulatory efficiency. A greater degree of acidosis lasting for longer periods was observed during poor cardiac output states. When output is adequate to maintain pressures compatible with adequate flow, blood $\mathrm{pH}$ values are less severely disturbed. Further, when arterial resistance least impairs flow (at low resistance values), cardiac work occurs with least effort, and thus, at a high rate of efficiency, sparing cardiac strain while enhancing tissue perfusion.

It is worthy of mention here that perhaps the whole story is not told by cardiovascular dynamics. In Figure 4 it can be observed that dog \#23, despite a near return to initial values of cardiac output, indicating adequate peripheral blood flow, did not survive the entire post-infusion period. Later blood evaluations indicated an elevated $P_{\mathrm{co}_{2}}$ ( $92 \mathrm{~mm} . \mathrm{Hg}$ ), which in retrospect leads us to conclude that adequate attention should also be paid to ventilatory dynamics. Impaired or depressed respiratory exchange could have contributed to the mortality rate, particularly since favourably altered cardiodynamics suggested the likelihood of more favourable outcome in this animal. Some mention must also be made of

\section{TOTAL PERIPHERAL RESISTANCE in SURVIVING DOGS}

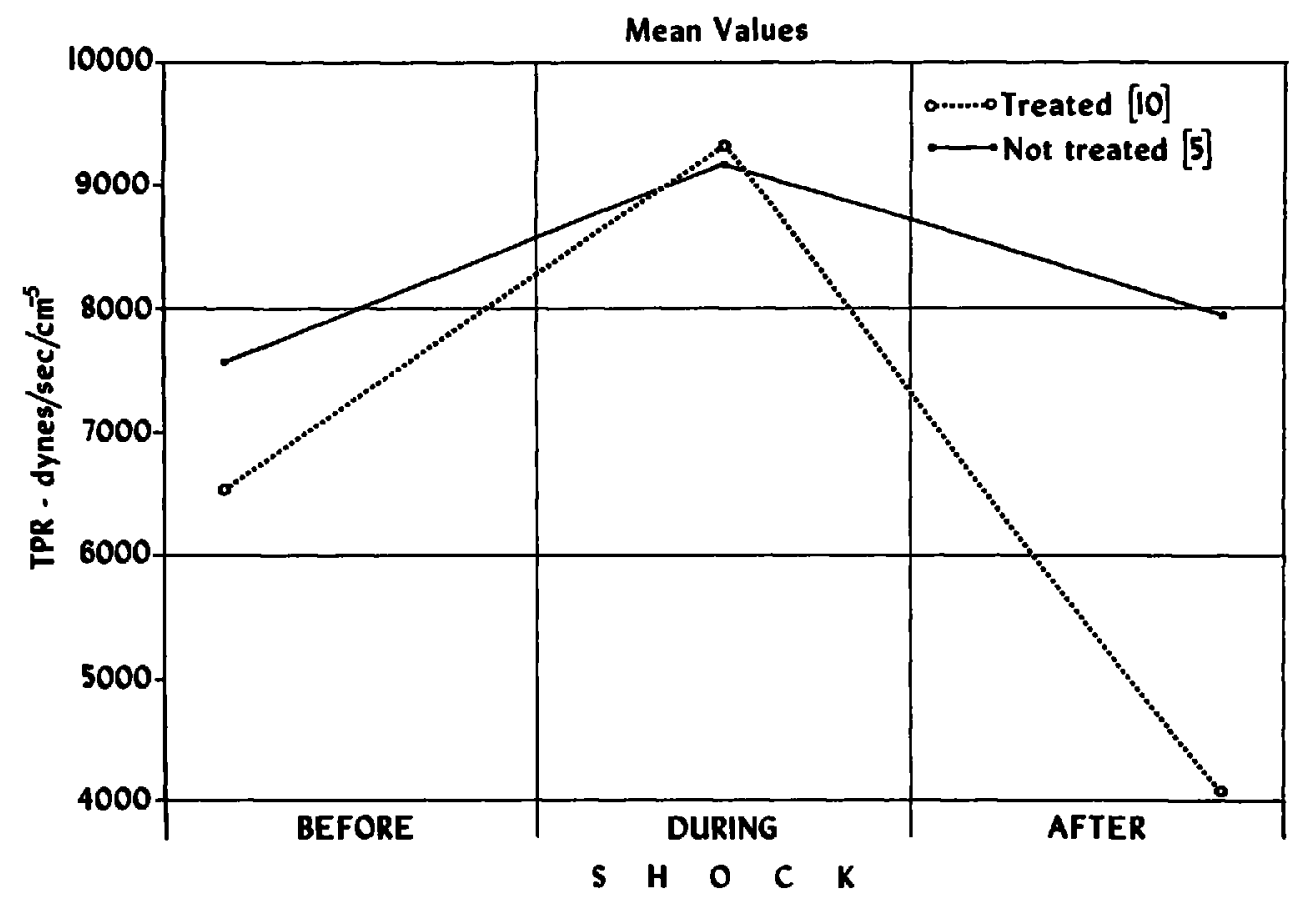

Ficure 5. Total peripheral resistance (mean values) is shown to decrease after blood retransfusion in the animal treated with Nylidrin $\mathrm{HCl}$. It rises slightly in dogs not treated. 
volume replacement. Blood volumes necessary to restore supported haemodynamic function may exceed normally expected blood volumes. Discrepancies between directly measured and/or calculated blood volumes and central venous pressures may be due to peripheral pooling with decreased venous return. In this regard, we share with L. D. MacLean and associates ${ }^{11}$ the opinion that measurements of central venous pressure should take precedence over other observations on blood volume in dictating volume replacement. Restricting our procedure to the replacement of let blood may have cost the lives of some of our treated animals, for it was felt that additional volume replacement could have supported returning haemodynamics.

No consideration of shock can overlook the impact of tissue ischaemia upon the biochemical aberrations induced in peripheral function and oxygen utilization. Metabolic acidosis is considered the by-product of accumulation of metabolic wastes and a deficient supply of oxygen to the tissues. The blood $\mathrm{pH}$ and the bicarbonate bases decline while fixed-acid metabolite concentration increases. Respiratory insufficiency caused by alterations in pulmonary ventilation may further compromise the maintenance of acid-base balance. It is almost certain that metabolic acidosis resulting from shock affects the performance of the enzyme system and thus induces further metabolic and physiologic alterations. For example, it is recognized that acidosis alters sodium, potassium, and calcium intra- and extra-cellular transport, producing disturbing effects on myocardial contractility and on all tissues generally. ${ }^{12}$ Results obtained by various investigators do not always agree on the survival rate of animals even after the effects of the arterial blood $\mathrm{pH}$ have been compensated for during the various episodes of experimental shock. However, there is general agreement that the metabolic acidosis of shock should be reversed by appropriate respiratory or metabolic means for maximum benefit.

Severe metabolic acidosis is a cardinal sign of irreversible shock persisting after re-infusion and even after sodium bicarbonate has been administered. This was observed in nearly all of our cases. Other writers have shown that the increase in blood lactate during shock, or the high concentration of lactic acid after re-transfusion, was evidence of severe metabolic acidosis and/or of the irreversible stage. ${ }^{13}$

As total recovery possibly best reflects the speed of tissue hypoxia restriction, more extensive consideration may be given to the use of hyperbaric chambers to increase oxygen delivery to damaged tissues.

\section{SUMMARY}

In the assessment of classical haemorrhagic shock in twenty-two dogs, thirteen of them treated with Nylidrin $\mathrm{HCl}$, ten survived extended episodes of arterial hypotension down to a mean arterial pressure of $40 \mathrm{~mm}$. Hg. Of nine control animals (untreated), five survived the re-infusion period. In the course of our study, Nylidrin $\mathrm{HCl}$ displayed two important pharmacodynamic effects:

1. It stimulated peripheral tissue arterial inflow, thus assisting metabolic exchange and reducing the peripheral anoxia of circulatory failure which aggravates metabolic acidosis. 
2. It significantly increased cardiac output.

Nylidrin $\mathrm{HCl}$ improves myocardial contractility and reduces peripheral arterial resistance. Slight increases in cardiac rate were also noted, along with a moderate decrease in arterial blood pressure. However, neither change proved to be statistically significant. Both groups were compared during and after shock to evaluate contributions to therapy afforded by a Beta stimulatory sympathomimetic agent.

\section{RÉSUMÉ}

Les résultats de cette étude sur le choc hémorragique chez vingt-deux chiens ont démontré que dix d'entre eux, traités par l'hydrochlorure de Nylidrin (77\%), ont survécu des épisodes d'hypotension artérielle sévère de $40 \mathrm{~mm}$.Hg (moyenne). Du groupe témoin composé de neuf chiens, cinq ont survécu sans traitement.

Dans notre étude, ce médicament a eu deux actions pharmaco-dynamiques importantes:

1. D'augmenter le débit sanguin capillaire périphérique, tout en augmentant les échanges métaboliques et diminuant l’anoxie stagnante prolongée qui aggrave l'acidose métabolique.

2. Il augmente le débit cardiaque de façon significative.

L'hydrochlorure de Nylidrin augmente la contractilité du myocarde et diminue la résistance artérielle périphérique. L'on note aussi qu'il y a une légère augmentation du pouls cardiaque et une légère diminution de la tension artérielle moyenne; toutefois, ces changements ne se sont avérés que peu significatifs. Les deux groupes ont été comparés avant, pendant et après le choc hémorragique pour évaluer l'action thérapeutique d'un agent bêta-sympathomimétique.

\section{ACKNOWLEDGMENTS}

We are indebted to Mrs. C. P. Nadeau for secretarial work, and to T. E. Racine and C. Lemay for technical help.

\section{REFERENCES}

1. Vick, J. A.; Cruchta, H. P.; Merickra, J. H.; et al. Vasodilator Therapy in Acute Hemorrhagic Shock. Circ. Res. 16: 58 (1965).

2. Danoff, D. S. \& GReEne, N. M. Vasodilation and the Metabolic Response to Hemorrhage. Surgery 55: 820 (1964).

3. Talaat, S. M.; Massion, W. H.; \& Scamlnng, J. A. Effects of Adenosine Triphosphate Administration in Irreversible Hemorrhagic Shock. Surgery 55: 813 (1964).

4. Aflquist, R. P. A Study of the Adrenotropic Receptors. Am. J. Physiol. 153: 586 (1948).

5. Rosenblum, W. I. \& Zwenfach, B. W. Cerebral Microcirculation in the Mouse Brain. Arch. of Neurol. 9: 414 (1963).

6. Deckêne, J. P.; Hebert, C.; \& McCrish, A. Halothane-Ether in Cardiac Surgery. Can. Anaesth. Soc. J. 9: 61 (1962).

7. Dechene, J. P. \& Hebert, C. Fluothane-Ether in Anaesthesia for Pulmonary Surgery. Can. Anaesth. Soc. J. 7: 100 (1960).

8. Hammton, W. F. Studies on the Circulation: IV. Further Analysis of the Injection Method, and of Changes in Hemodynamics Under Physiologic and Pharmacologic Conditions. Am. J. Physiol. 99: 534 (1932).

9. Sigganad-Andersen, $O$. Blood Acid-Base Alignment Nomogram. Scand. J. Clin. Lab. Invest. 15: 211 (1963).

10. Courtice, F. C. The Blood Volume of Normal Animals. J. Physiol. 102: 290 (1943). 
11. Maclean, L. D.; Dufr, J. H.; Scott, H. M.; \& Peretz, D. I. Treatment of Shock in Man Based on Hemodynamic Diagnosis. Surg. Gynec. \& Obst. 120: 1 (1965).

12. Downinc, S. E.; TAlner, N. S.; \& Gardner, T. H. Cardiovascular Responses to Metabolic Acidosis. Am. J. Physiol. 208: 237 (1965).

13. Peretz, D. I.; McGrecon, M.; \& Dossetor, J. B. Lacticacidosis: A Clinically Significant Aspect of Shock. Canad. M.A.J. 90: 673 (1964).

14. KorEIn, Junnus. Effects of a Vasoactive Drug (Nylidrin $\mathrm{HCl}$ ) on the Response of Electroencephalogram to Hyperventilation. Arch. Neurol. In press.

15. WhrtTiER, J. R. \& Dhormorts, A. The Effect of Cyclandelate, Isoxsuprine and Nylidrin on Hyperventilation Build up in the Electroencephalogram of Volunteer Subjects. Angiology 16, no. 10 (1965).

16. Telcker, F. (Arlington-Funk Laboratories). Personal Communication. 